\title{
DIMENSIONAMENTO DE UM SISTEMA MICRO-ONDAS PARA DISTRIBUIÇÃO DE SINAIS DE TV DIGITAL USANDO O SOFTWARE RADIO MOBILE ${ }^{\circledR}$
}

\author{
André Antônio dos Anjos ${ }^{1}$ \\ Ricardo Augusto da Silva Junior ${ }^{2}$ \\ Rodrigo Cogliatti ${ }^{3}$
}

\begin{abstract}
RESUMO
Neste artigo é demonstrado um exemplo de dimensionamento de um sistema de micro-ondas com o objetivo de ligar as cidades sul-mineiras de Varginha, Santa Rita do Sapucaí e Pouso Alegre, fazendo uso do Software Radio Mobile. Os parâmetros usados nas simulações são baseados nas especificações de equipamentos reais utilizados na distribuição de sinais de Televisão Digital no Brasil.
\end{abstract}

Palavras-chave: Link budget. Point-to-point. TV Digital. Radio Mobile.

\section{DIMENSIONING A MICROWAVE SIGNAL DISTRIBUTION SYSTEM FOR DIGITAL TV USING RADIO MOBILE SOFTWARE ${ }^{\circledR}$}

\begin{abstract}
This paper presents a designing example of a microwave system with the objective to connect three towns located in the south of Minas Gerais State namely, Varginha, Santa Rita do Sapucai and Pouso Alegre, making use of Radio Mobile Software. The parameters used in the simulations are based on real equipment specifications for signal distribution Digital TV in Brazil.
\end{abstract}

Keywords: Link budget. Point-to-point. Digital TV. Radio Mobile.

\section{INTRODUÇÃO}

O uso de recursos computacionais está cada vez mais difundido em todos os ramos da engenharia, trazendo maior confiabilidade e precisão para os projetos por intermédio de

\footnotetext{
${ }^{1}$ Doutorando pela Unicamp, mestre em Telecomunicações pelo Instituto Nacional de Telecomunicações (Inatel). Atua como Engenheiro Especialista em Sistemas no Inatel Competence Center E-mail: andre-anjos@inatel.br ${ }^{2}$ Mestre em Telecomunicações pelo Instituto Nacional de Telecomunicações (Inatel). Professor do Núcleo de Ensino à distância em TV digital do Inatel. E-mail: ricardojunior@inatel.br.

${ }^{3}$ Mestre em Telecomunicações pelo Instituto Nacional de Telecomunicações (Inatel). E-mail: cogliatti@inatel.br.
} 
simulações cada vez mais realistas. Como resultado, a abordagem de projetos baseada em simulações apresenta vantagens como a redução de custos dos protótipos e prevenção contra erros que surgem no ambiente de operação. Em telecomunicações, é comum o uso de softwares que possibilitam a simulação de sistemas complexos, facilitando sua organização e implementação. Para simulação de enlaces ponto-a-ponto, o software Radio Mobile ${ }^{\circledR}$ (RADIO MOBILE, 2014) é muito utilizado para fins acadêmicos e até mesmo profissionais, possuindo uma ampla gama de recursos e funcionalidades. Em Trandafir (2010), demonstra-se o uso do software para a análise de uma rede pública de internet Wi-fi. É importante acrescentar que o software Radio Mobile ${ }^{\circledR}$ leva em conta a topografia da região, incluindo alguns aspectos morfológicos, fator importante para projetos mais realistas (RIBEIRO, 2004). A Figura 1 mostra uma tela inicial do software Radio Mobile ${ }^{\circledR}$ com os recursos de análise de viabilidade de enlaces em redes de telecomunicações. Com o Radio Mobile ${ }^{\circledR}$ é possível projetar sistemas de telecomunicações e verificar o desempenho de sistemas de rádios incluindo informações sobre a topografia do terreno, tipo de relevo, condições de propagação, entre diversas funcionalidades.

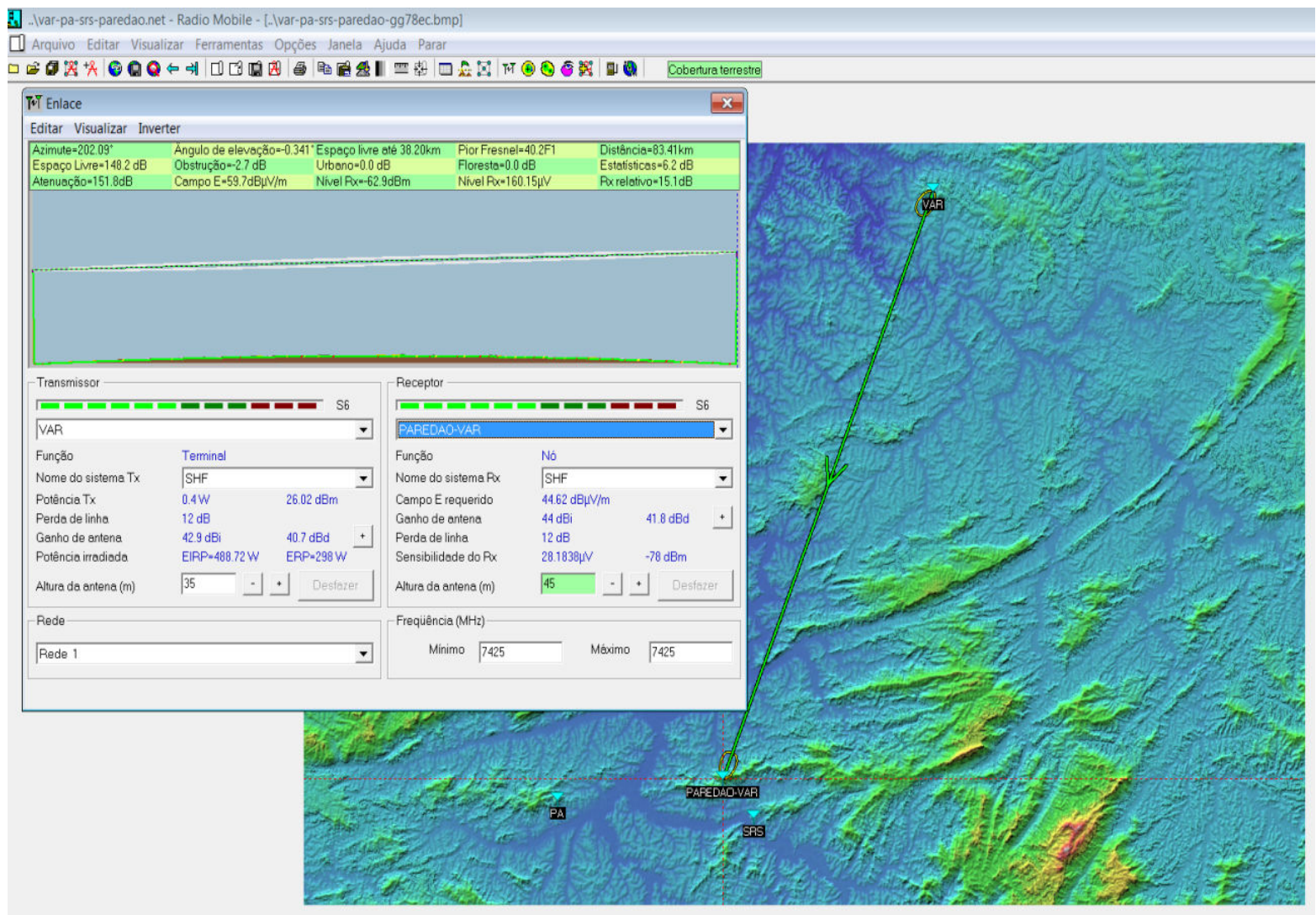

Figura 1 - Tela inicial do Radio Mobile com a demonstração da ferramenta de análise de enlace rádios Fonte: Software Radio Mobile ${ }^{\circledR}$ 
O objetivo deste artigo é evidenciar a utilização do Radio Móbile ${ }^{\circledR}$ no projeto de um sistema micro-ondas (POZAR, 2011), cuja finalidade é distribuir o sinal de TV Digital no padrão ISDB-Tв (TAKADA; SAITO, 2006) para as cidades sul-mineiras de Varginha, Pouso Alegre e Santa Rita do Sapucaí. Um dos maiores desafios da implantação do sistema de TV Digital no Brasil é justamente o processo de interiorização (AMOEDO, 2011), uma vez que o plano de implantação ocorre em escala nacional. O primeiro passo consiste em caracterizar corretamente o sistema de distribuição, coletando informações sobre os pontos de transmissão e recepção em termos de operação, para uma posterior simulação do enlace no software. Um bom tutorial para uso do Radio Mobile pode ser encontrado em Salamanca (2011).

\section{DIMENSIONAMENTO DO SISTEMA}

O dimensionamento será feito com base na distribuição de sinais de TV digital. O objetivo será transmitir o sinal Broadcast Transport Stream (BTS) para outras cidades por meio da utilização de um link de micro-ondas, para sua posterior radiodifusão. O sinal de alta velocidade gerado internamente na emissora será codificado e encaminhado ao multiplexador ISDB-Tв (FERREIRA, 2009). Em seguida, o fluxo de dados BTS, gerado pelo Mux-ISDBTB, será encaminhado ao link de micro-ondas digital para transmissão.

Toda a parte de codificação para formação do fluxo BTS está localizada na cidade de Varginha. O nó de distribuição instalado na Serra do Paredão é responsável por receber o fluxo BTS de Varginha via micro-ondas e distribuí-lo para as cidades de Santa Rita do Sapucaí e Pouso Alegre, conforme pode ser observado na Figura 2. Os sistemas micro-ondas são: Link I, II e III, retratando os enlaces entre o nó Serra do Paredão e os terminais Varginha, Pouso Alegre e Santa Rita do Sapucaí, respectivamente. 


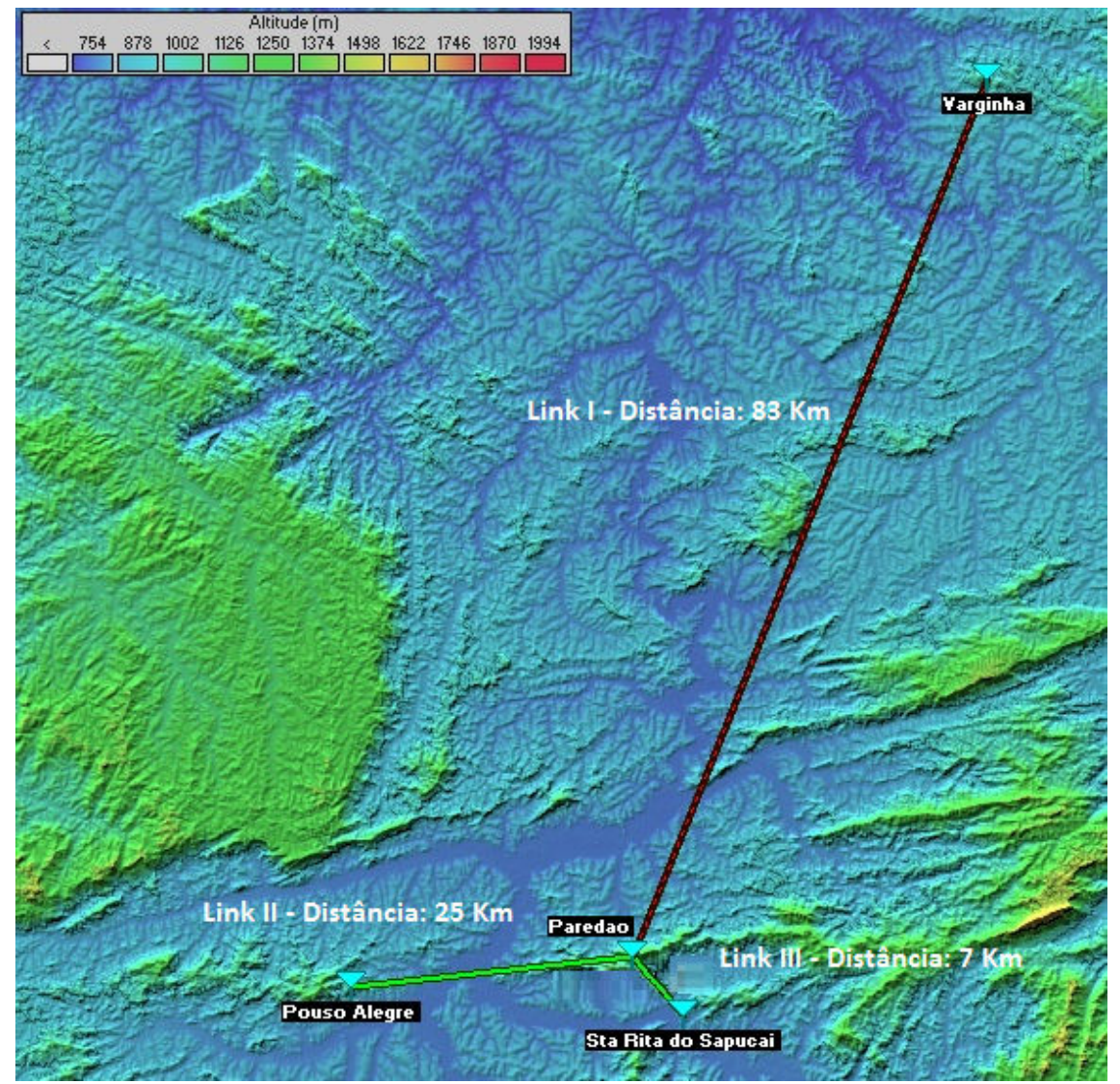

Figura 2 - Descrição do nó e dos terminais envolvidos no projeto, além das circunstâncias envolvidas Fonte: Software Radio Mobile ${ }^{\circledR}$

\subsection{Equipamentos utilizados}

Foram escolhidas duas soluções de micro-ondas do fabricante-empresa Hitachi Kokusai Linear ${ }^{\circledR}$ O equipamento IST7G50P5 para o sistema de transmissão e o ISR7G5000 para a recepção. Estas soluções foram desenvolvidas para aplicações de TV Digital do sistema ISDB-TB. As especificações dos equipamentos podem ser encontradas no catálogo de produtos da empresa (HITACHI, 2010), e as mais relevantes para a simulação são mostradas na Figura 3. O sistema irradiante é retratado pelas etapas de conectorização, cabos, guias, divisores e outros componentes que serão contabilizados no link budget do projeto.

No projeto de transmissão via micro-ondas da rede de distribuição, será utilizado o mesmo setup de transmissão e recepção nos pontos (terminais) da rede, a fim de facilitar o dimensionamento e aquisição dos equipamentos junto aos fabricantes. Será utilizada a antena RFS DA8-W71AC, com 44dBi de ganho, cujas especificações e diagrama de irradiação podem ser encontradas no catálogo de produtos do fabricante-empresa Radio Frequency Systems (RFS, 2012). 


\section{Análise do Sistema \\ Informações e Dimensionamento}

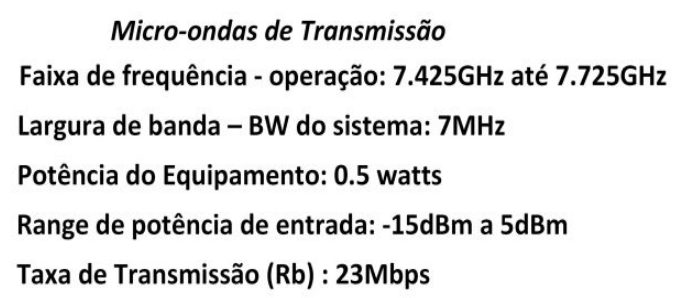

Micro-ondas de Transmissão

Faixa de frequência - operação: $7.425 \mathrm{GHz}$ até $7.725 \mathrm{GHz}$

Largura de banda - BW do sistema: $7 \mathrm{MHz}$

Potência do Equipamento: 0.5 watts

Range de potência de entrada: $-15 \mathrm{dBm}$ a $5 \mathrm{dBm}$

Taxa de Transmissão (Rb) : 23Mbps

Micro-ondas de Recepção

Faixa de frequência - operação: $7.425 \mathrm{GHz}$ até $7.725 \mathrm{GHz}$ Sensibilidade do Receptor: $-78 \mathrm{dBm} /$ Operação TEB < 10e- 6 Figura de ruído do receptor $<4 \mathrm{~dB}$ (Projeto: $4 \mathrm{~dB}$ ) TEB - Taxa de erro de bit ou BER - Bit Error Rate Nível máximo de Entrada $=-35 \mathrm{dBm}$
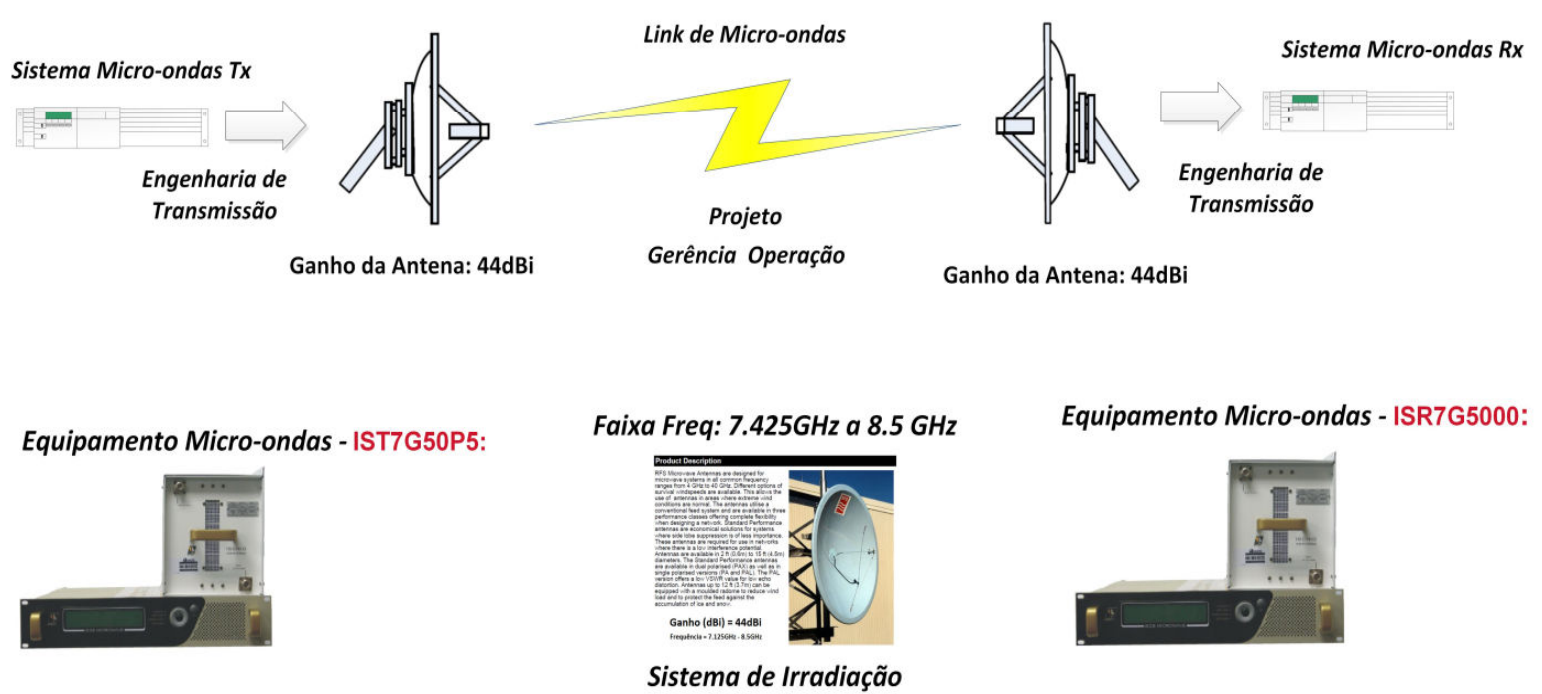

Equipamento Micro-ondas - ISR7G5000:

Figura 3 - Especificações dos equipamentos escolhidos para dimensionamento do sistema micro-ondas

O principal objetivo do projeto é desenvolver seu dimensionamento de tal forma a assegurar um nível de recepção maior que a sensibilidade dos sistemas micro-ondas de recepção. Assim, o projeto do sistema visa atender esse parâmetro (Sensibilidade de recepção $\left.\rightarrow \mathrm{S}_{\mathrm{rx}}=-78 \mathrm{dBm}\right)$, que também pode ser verificado na Figura 3. Isso significa que se o sistema micro-ondas operar com nível de recepção acima de $-78 \mathrm{dBm}$, tem-se o sucesso na demodulação dos sinais de TV Digital que foram transmitidos. Junto ao parâmetro de sensibilidade de recepção, a taxa de erro de bit alvo (TEB ou BER target) também é um indicador do desempenho do sistema micro-ondas.

\section{SIMULAÇÕES DOS ENLACES}

Em um primeiro momento, tem-se a análise das simulações para frequências entre $7.425 \mathrm{GHz}$ e $7.725 \mathrm{GHz}$ com antenas de ganho $44 \mathrm{dBi}$ operando com potência de transmissão de 400mW, o qual é um nível relativamente baixo para operação e dentro dos limites impostos pela regulamentação vigente. Os lugares escolhidos para a instalação das antenas já são 
comumente empregados para este fim, sendo as alturas escolhidas para as torres de $35 \mathrm{~m}$ para os terminais (nós) e 45m para o nó localizado na Serra do Paredão. O diagrama de irradiação das antenas utilizadas na simulação foi editado conforme as especificações do diagrama da antena escolhida para o projeto.

\subsection{Link I - Varginha à Serra do Paredão}

A Figura 4 mostra a simulação para o Link I, o qual interliga a cidade de Varginha à Serra do Paredão. Trata-se da maior distância envolvida no projeto, retratada por um link cuja distância é de $83 \mathrm{~km}$. A simulação foi configurada com uma potência de transmissão de $26 \mathrm{dBm}(400 \mathrm{~mW})$ e uma perda devido a atenuações nos cabos, conectores e guias de $7 \mathrm{~dB}$. A figura de ruído do receptor foi configurada em $4 \mathrm{~dB}$. O nível de sinal de recepção estimado é de aproximadamente $-54 \mathrm{dBm}$, viabilizando o link de comunicação com uma atenuação total de $154 \mathrm{~dB}$. A simulação mostra uma margem de operação maior que $20 \mathrm{~dB}$ (Rx Relativo de $24 \mathrm{~dB})$ frente à sensibilidade do receptor $(-78 \mathrm{dBm})$. Essa folga de operação é importante para problemas inesperados, como atenuação por chuvas, por exemplo. Vale ressaltar que o Link I está sem obstáculos interferindo na primeira zona de Fresnel (RIBEIRO, 2004). A título de complementação, é possível investigar no simulador em quais condições de configuração têmse uma operação próxima do limiar de sensibilidade de recepção. Assim, considerando a mesma potência de transmissão e alterando-se os ganhos das antenas envolvidas para $29 \mathrm{dBi}$, por exemplo, o nível de sinal recebido se reduz para aproximadamente $-84 \mathrm{dBm}$, inviabilizando a transmissão, uma vez que não se satisfaz a condição de sensibilidade mínima de recepção do sistema micro-ondas em questão.

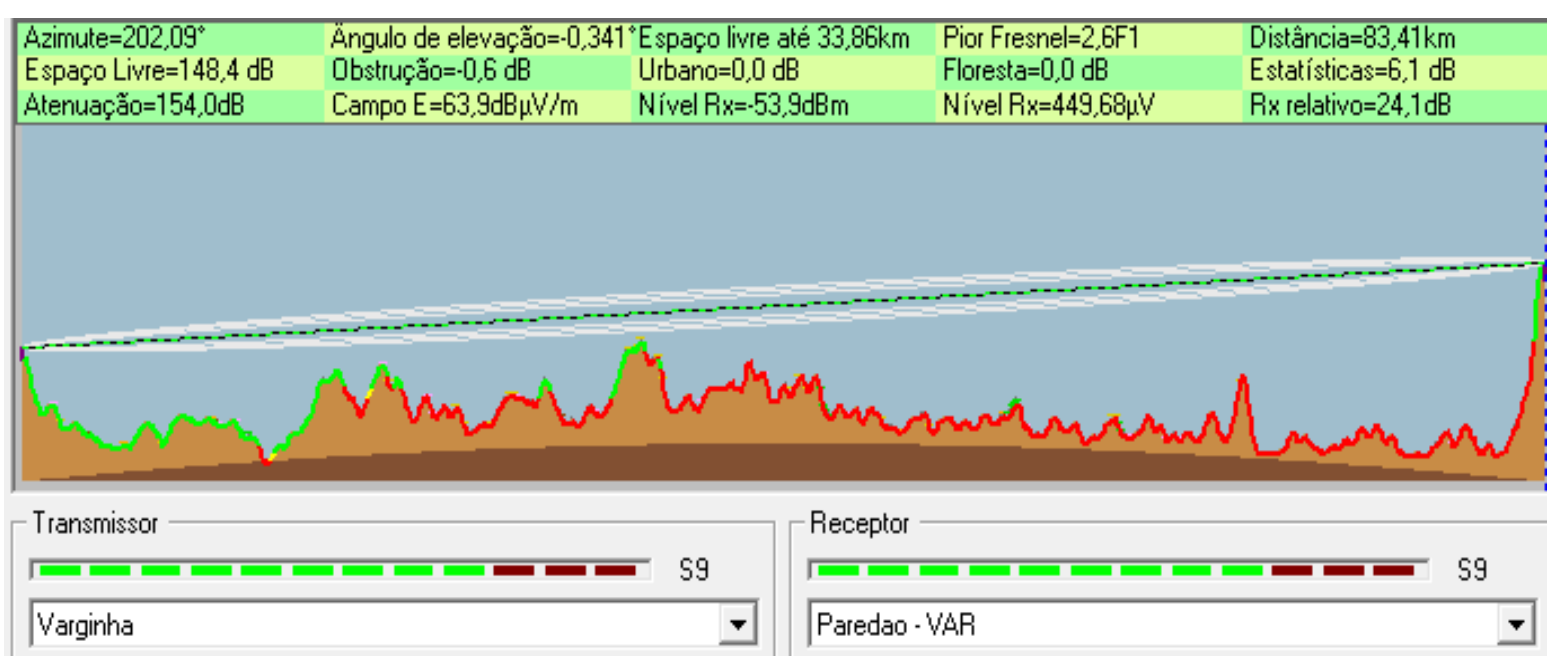

Figura 4 - Simulação e análise de enlace do Link I no Radio Mobile

Fonte - Software Radio Mobile ${ }^{\circledR}$

ForSci.: r. cient. IFMG campus Formiga, Formiga, v. 2, n. 1, p. 68-78 jan./jun. 2014. 


\subsection{Link II - Serra do Paredão a Pouso Alegre}

A distância do Link II é de quase $25 \mathrm{~km}$. A atenuação de $7 \mathrm{~dB}$ foi mantida no ponto de Pouso Alegre, porém, o nó de transmissão da Serra do Paredão possui um maior número de fatores que aumentam sua atenuação. Em Hitachi (2010), pode-se coletar informações sobre a atenuação do guia de ondas, gerando uma perda aproximada de $2.5 \mathrm{~dB}$, que é somada a perda de $3 \mathrm{~dB}$ do divisor e do sistema de recepção micro-ondas. Como resultando, estima-se uma atenuação total de $12 \mathrm{~dB}$ no nó de distribuição. A Figura 5 mostra a simulação para o Link II, com uma potência de recepção de aproximadamente $-50 \mathrm{dBm}$, em conformidade com a sensibilidade do receptor, gerando um Rx relativo de 27,7 dB. Essa margem de operação frente à sensibilidade garante a viabilidade do enlace e pode ser explorada no lado da recepção por intermédio de planos de otimização para redução de custos no sistema. Seria possível, por exemplo, o uso de uma antena de ganho $33 \mathrm{dBi}$ e, ainda assim, poder-se-ia garantir a operação no limiar de recepção.

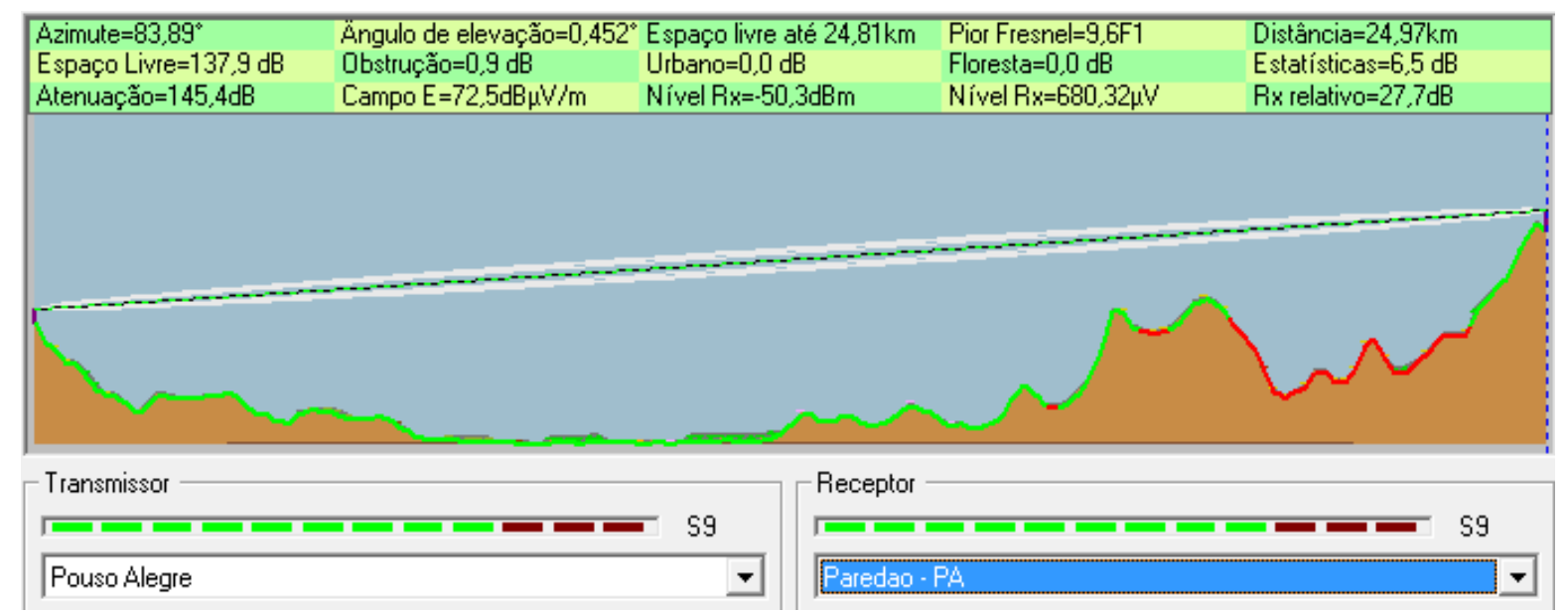

Figura 5 - Simulação e análise de enlace do Link II no Radio Mobile

Fonte: Software Radio Mobile ${ }^{\circledR}$

\subsection{Link III - Serra do Paredão a Santa Rita do Sapucaí}

As mesmas considerações de perda feitas para o Link II são repetidas para o Link III. Nota-se que a distância deste link é bem menor que os demais $(7 \mathrm{~km})$ e uma antena de menor ganho também pode ser utilizada a fim de reduzir custos. A Figura 6 mostra a simulação do enlace para um sistema de antenas com ganho de 29dBi (cada). O nível de recepção é de aproximadamente $-69 \mathrm{dBm}$, retratando quase $10 \mathrm{~dB}$ de folga para eventuais problemas e perdas no próprio sistema micro-ondas. O uso de antenas com ganho de $44 \mathrm{dBi}$ resulta em níveis de ForSci.: r. cient. IFMG campus Formiga, Formiga, v. 2, n. 1, p. 68-78 jan./jun. 2014. 
recepção da ordem de $-39 \mathrm{dBm}$, gerando uma margem de mais de $30 \mathrm{~dB}$ em relação à sensibilidade de recepção. Em casos nos quais existe o objetivo de aumentar a robustez do enlace e as margens de segurança do Link, pode ser interessante trabalhar com a configuração caracterizada por antenas de maiores ganhos.

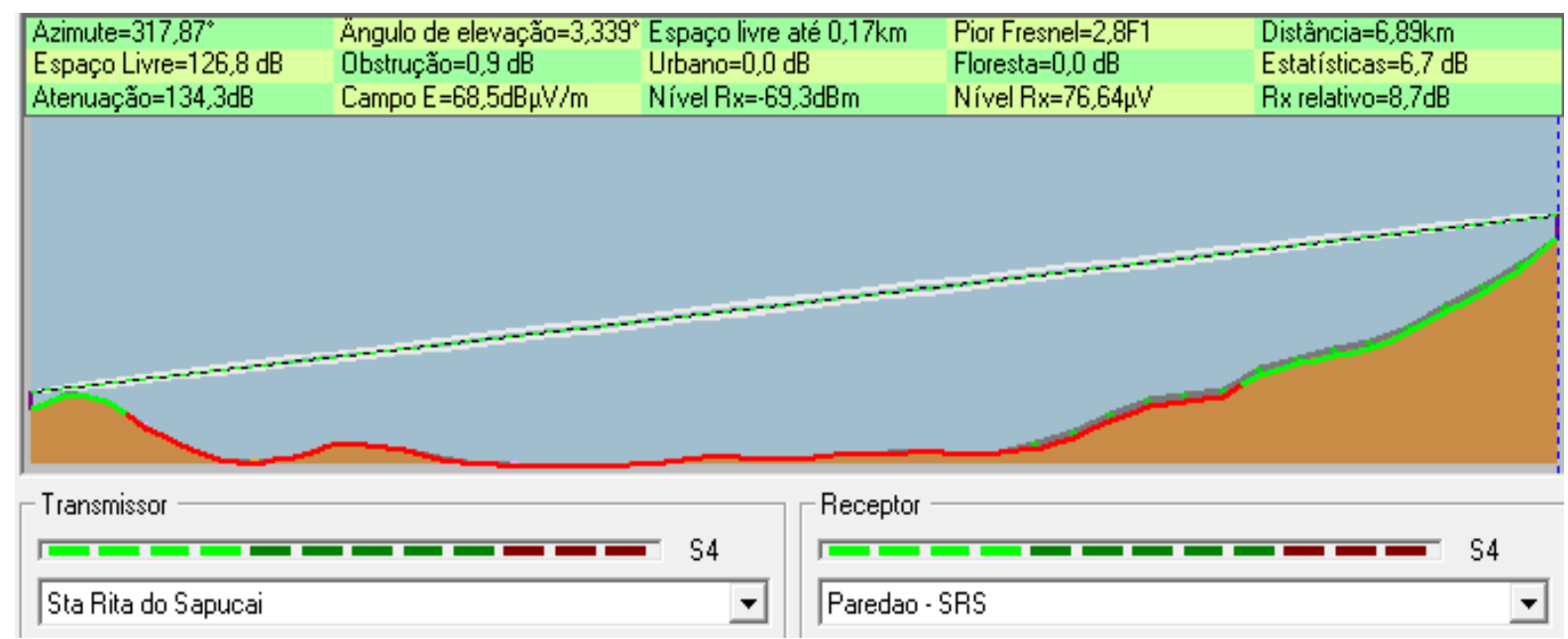

Figura 6 - Simulação e análise de enlace do Link III no Radio Mobile

Fonte: Software Radio Mobile ${ }^{\circledR}$

\section{RESULTADOS E DISCUSSÃO}

A análise dos Links I, II e III para distribuição do sinal BTS via de rede de microondas permite encontrar os pontos críticos de operação que podem comprometer a retransmissão dos sinais de TV Digital. A preocupação principal em um projeto de distribuição de sinais de TV consiste no correto dimensionamento dos enlaces quanto ao requisito de sensibilidade de recepção, uma vez que, em alguns casos, podem ser necessários mais estágios de micro-ondas para as retransmissões, elevando a complexidade da rede e, ao mesmo tempo, aumentando-se as perdas. A correta recepção do sinal BTS nos pontos de distribuição é essencial para que os sinais de TV Digital possam ser retransmitidos para a população via radiodifusão. Neste sentido, foi constatado que com as distâncias envolvidas e os equipamentos utilizados é possível dimensionar os Links de distribuição com margens de segurança, que podem ser utilizadas para otimizar os custos do projeto. Um dos principais pontos de análise para redução dos custos é a composição de todo o sistema irradiante, contemplando as linhas de transmissão e antenas. Ainda assim, seria interessante comparar as análises do sistema que opera em $7 \mathrm{GHz}$ com a aplicação do projeto em frequências mais baixas que resultam em menor atenuação na propagação dos sinais. 
A Figura 7 mostra um quadro comparativo que relaciona os Links de distribuição I, II e III para as frequências de $7 \mathrm{GHz}$ e $2.5 \mathrm{GHz}$. O ganho das antenas também é informado, bem como os resultados de simulação do nível de recepção atingido por cada Link, o qual leva à comprovação de viabilidade ou não dos enlaces.

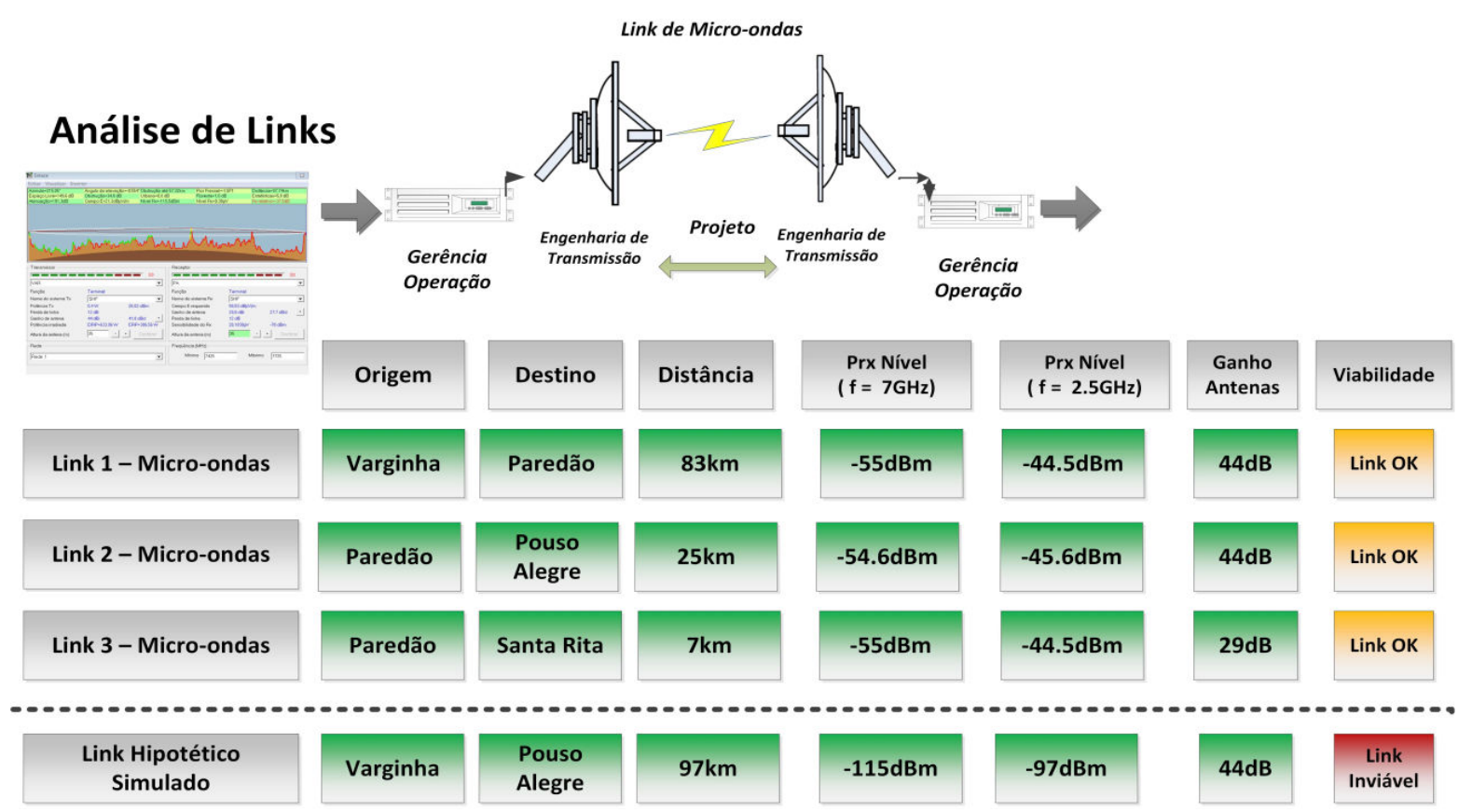

Figura 7 - Análise do sistema de micro-ondas tabela comparativa entre Links

A atenuação do espaço livre para a frequência de 2.5GHz é menor (RIBEIRO, 2004), resultando em um nível de recepção maior nos sistema micro-ondas de recepção. O aumento de margem de segurança, oriundo da operação em frequência mais baixa, abre espaço para planos ainda mais eficientes para a redução de custos de todo o sistema irradiante, com antenas e guias de onda mais baratos. É possível fazer uma análise comparativa com a simulação de um Link hipotético que ligaria o ponto de transmissão de Varginha direto ao terminal de Pouso Alegre. Para o mesmo sistema de antenas, potência de transmissão e operando em frequências mais baixas, têm-se um nível de sinal recebido $(-97 \mathrm{dBm})$ fora do alcance de sensibilidade do sistema micro-ondas de recepção $(-78 \mathrm{dBm})$. Esta é a principal razão da elaboração de uma estratégia de rede de distribuição que contempla o planejamento do nó de distribuição na Serra do Paredão, pois este está mais perto de Varginha e, ao mesmo tempo, possui uma altura razoável com vista para as cidades-alvo do projeto de distribuição. 


\section{CONCLUSÃO}

O Brasil está passando por um processo de implantação do sistema de TV Digital em escala nacional e um dos maiores desafios é justamente a interiorização dos sinais digitais. De acordo com o cronograma de implantação apresentado, está programado o switch-off analógico (desligamento dos transmissores de TV analógico) para o ano de 2018, aumentando ainda mais o desafio para as emissoras. Neste sentido, a regionalização e distribuição dos sinais de TV Digital para as pequenas cidades devem estar dentro do escopo de estratégia de cobertura por partes das emissoras. A busca e pesquisa por soluções eficientes de transmissão e distribuição de sinais de telecomunicações se fazem necessária. Cenários de transmissão empregando redes de telecomunicações, enlaces de satélite e links de micro-ondas se apresentam como algumas soluções utilizadas no contexto brasileiro, e cada caso de distribuição é único, exigindo diferentes análises que culminam na relação custo-benefício para as operadoras/emissoras de TV Digital. Dentro dessa análise, o correto dimensionamento dos sistemas de radio-enlace ponto-a-ponto e simulação destes sistemas podem revelar informações interessantes, que viabilizam projetos de baixo custo para as emissoras, satisfazendo os requisitos de transmissão e distribuição de sinais de TV Digital. De forma comparativa, os orçamentos e análises derivados destes projetos de simulação de sistemas de micro-ondas podem ser comparados com os custos de outras soluções, como satélite, por exemplo, dando mais confiança na melhor escolha da solução para a interiorização do sinal ISDB-TB.

\section{REFERÊNCIAS}

AMOEDO, M. Os desafios da interiorização e regionalização da TV Digital no Brasil. Revista da SET, n. 120, 2011. Disponível em: <http://www.set.com.br/artigos/ed120/ed120 _tvdigital.htm.>. Acesso em: abr. 2014.

FERREIRA, J. S. Uma proposta de implementação do multiplexador do sistema ISDBTB. 2009. 121f. Dissertação (Mestrado em Telecomunicações) - Instituto Nacional de Telecomunicações (Inatel), Santa Rita do Sapucaí-MG, 2009.

HITACHI KOKUSAI LINEAR. Catálogo de produtos da empresa Hitachi Kokusai Linear. 2010. Disponível em: $<$ http://linear-tv.com/portuguese/products_2/isdb-t/>. Acesso em: abr. 2014. 
POZAR, D. Microwave Engineering. 4. ed. [S.1.]: Wiley, 2011.

RADIO MOBILE WEB SITE. Tutorial de utilização e download do software Radio

Mobile. Disponível em: <http://www.cplus.org/rmw/english1.html>. Acesso em: abr. 2014.

RFS (RADIO FREQUENCY SYSTEMS). AWS Microwave antenna system relocation kit: catálogo: key products for $7 \mathrm{GHz}$ point-to-point applications, 2012. Disponível em:

$<\mathrm{http}$ ://www.rfsworld.com/userfiles/pdf/7ghz_aws_relocation_kit.pdf.>. Acesso em: abr. 2014.

RIBEIRO, J. A. J. Propagação das ondas eletromagnéticas: princípios e aplicações. 1. ed. São Paulo: Érica, 2004.

SALAMANCA, L.; FUENTES, J. J. M.; OLMOS, P. M. Review of the Radio Mobile Software as a teaching tool for Radio planning. IEEE Multidisciplinary Engineering Education Magazine, v. 6, n. 2, June 2011.

TAKADA, M.; SAITO, M.Transmission System for ISDB-T. Proceedings of the IEEE, v. 94, n. 1, January 2006.

TRANDAFIR, B.; FRATU, O.; HALUNGA, S. Simulation and analysis of a Wi-Fi public network using the Radio Mobile Software. In: INTERNATIONAL SYMPOSIUM IEEE ELETRONICS AND TELECOMMUNICATIONS (ISETC), 9., 2010, Timisoara.

Proceedings... Timisoara: [s.n.], p. 281-284.

Recebido em: 06/04/2014

Aprovado em: 25/05/2014 